\title{
Interactive comment on "Development and evaluation of pollen source methodologies for the Victorian Grass Pollen Emissions Module VGPEM1.0" by Kathryn M. Emmerson et al.
}

\section{Anonymous Referee \#1}

Received and published: 28 March 2019

General comments: This manuscript describes the implementation of several different emissions parameterizations to prognostically simulate grass pollen in one region of Australia. The paper is relatively narrow in scope in that it is focused on one type of pollen (grass) in one small region of the globe. That said, it will be useful model for the region and has the potential to be applied to other regions for grass pollen. My comments are mostly minor and regarding changes for clarity and additional supporting information. I recommend the article for publication following these revisions.

Comments on the analysis

1. Regarding the statistical model functions shown in Figure 4: It is helpful to see what 
the dependencies look like, but it is unclear how these meteorological factors physically relate to what we know about pollen emissions. Can these observed dependencies be related to any physical processes?

2. Risk category definitions: Page 4 - line 14 - Can you place these count categories (low, moderate, high, extreme) in context as compared to other counts in other regions (e.g., Europe, US)? This would give readers an idea of how high/low Australian counts are relative to other locations in the world. Additionally, for the evaluation based on risk categories on page 12 , how do uncertainties in these thresholds influence the analysis?

3. Page 6 line 24 - Any local evidence for why temperature would be increasing emissions? Because the temperature component seems to be driving the statistical models, it would be useful to understand why there is such a shift around $300 \mathrm{C}$.

4. Page 10 - line 29 - The explanation of the sharp drop off with temperature and the growing BL height doesn't make very much sense. Can you verify if these changes with time/temperature relate to the simulated PBL height by the model?

5. Page 12, lines 25-30: What are the relative magnitudes of $u$ and $v$ winds in the region? E.g, If the $u$ winds are higher than $v$ (as they frequently are), would that explain the improved correlations? Additionally, how does this relate to the wind parameterization that is implemented? E.g., if the magnitude of $v$ winds are always below the threshold, then this might explain the lack of correlation.

6. Page 13 - line 10: Can you explain why the modeled $\mathrm{RH}$ correlation would be higher given that the model simulated observed $\mathrm{RH}$ with good fidelity?

7. Page 13 (and conclusions, page 15 line 25)- It is unclear why wind speed is not a good predictor in your models. Can this be compared with other studies to place this finding in context.

8. Section 4.3: There is little discussion of why performance is different at the eight

Printer-friendly version

Discussion paper 
different sites. This could be expanded in a revised manuscript.

Editorial comments

1. Page 2 - line 1: Does this mean that throughout the world Melbourne has the highest population of allergy sufferers, or just in Australia? Does the reference support this? It appears to discuss the European community.

2. Page 2- lines 30-35: There are a few other dispersion model studies missing (e.g., oak study in CMAQ; Pasken and Pietrowitz, 2005)

3. Page 3 - line 10 - Does the lack of other wind-driven pollination species also apply to all other grasses? It is unclear if there are other Australian species that would be contributing to the grass pollen count outside of the ryegrass. My understanding is that different genuses of the Poaceae family are very hard to distinguish in daily counts.

4. Page 3 - line 30: Genus distinctions can be made based on volumetric sampling methods. Additionally, it would be helpful to note how many different pollen types (e.g, at the family or genus level) are counted at the Australian sites.

5. Page 6 - line 10 - Other studies (e.g., van Hout et al, 2008; Viner et al, 2010) have shown an early morning timing peak. Any ideas as to why ryegrass might be different?

6. Figure 2- It's hard to see the correlation between the EVI and pollen count. A climatological average would show the timing better.

7. Figure $4-$ Can you put the $\mathrm{V} 1$ and $\mathrm{V} 2 \mathrm{x}$ axes on the same scale to improve visual comparisons?

8. Page 9 - I'm confused about the loss factor in Equation 11 - how were these set, and how are they different from a regular deposition rate?

Printer-friendly version

9. Page 13 - lines 18-20: Move this text to the figure caption.

Discussion paper

References 
Pasken, R. and J.A. Pietrowiez (2005) Using dispersion and mesoscale meteorological models to forecast pollen concentrations, Atmos. Environ., 39, 2689-7701.

Van Hout et al., (2008) The influence of local meteorological conditions on the circadian rhythm of corn (Zea mays L.) pollen emission, agricultural and forest meteorology, 148, 1078-1092.

Viner, B.J., M.E. Westgate and R.W. Arritt, 2010: A model to predict diurnal pollen shed in maize. Crop Science 50, 235-245.

Interactive comment on Geosci. Model Dev. Discuss., https://doi.org/10.5194/gmd-2019-43, 2019. 